\title{
Pravni status univerze in njenih članic
}

UDK: 378:371:06

Niko Abrahamsberg

Fakulteta za upravo, Univerza v Ljubljani

niko.abrahamsberg@fu.uni-lj.si

\section{IZVLEČEK}

$\checkmark$ prispevku obravnava avtor pravni položaj univerze in njenih delov. Ugotavlja, da ta odstopa od pravnih ureditev $v$ svetu in pomeni neke vrste mešanico korporacije in zavoda. Posebej moti nejasen položaj delov univerze fakultet, akademij, visokih šol in drugih, ki jim zakon priznava korporacijski status članic, na drugi strani pa jih opredeljuje kot zavode. $S$ tem je povezan tudi nejasen pravni status "članic" univerze. Rešitve vidi avtor v sprejemu novega sistemskega zakona o zavodih in skladno $s$ tem $v$ ureditvi položaja javnih (državnih) univerz. Na drugi strani pa bi kazalo dopustiti možnost, da se zasebne visokošolske organizacije ustanovijo $v$ poznanih, zasebno pravnih statusnih oblikah in ne v obliki zavoda.

Ključne besede: korporacija, ustanova, zavod, univerza, fakulteta, pravna subjektiviteta, članica univerze, zasebni zavod

\section{Uvod}

Status organizacij, ki opravljajo dejavnost vzgoje in izobraževanja in druge tako imenovane družbene dejavnosti, ureja Zakon o zavodih (UI.RS 12/1991) kot splošen predpis. Statusno pravni položaj visokošolskih organizacij in torej tudi univerze ureja Zakon o visokem šolstvu (dalje ZViS; UI. RS 67/93, 39/95, 99/99, 64/2001) kot poseben predpis.

Pri proučevanju statusa univerze gre za vsebinska vprašanja povezana z njenim družbenim položajem in za vprašanja statusno pravnega organiziranja. S vsebinskega vidika ne gre le za načelen problem integriranosti ali dezintegriranosti, marveč za vprašanje take organizacijske strukture, ki bo zagotovila ohranitev vsebinske celote vseh disciplin ob možnosti samostojnega razvoja vsake izmed njih, kot ugotavlja Kranjc (Kranjc, 1999, str. 189). V naši razpravi se bomo omejili zgolj na statusno organizacijski vidik, ki pa je nujno povezan z družbenim dojemanjem univerze. 
Čeprav je zakon o visokem šolstvu nastal že $v$ času nove pravne ureditve $\checkmark$ Sloveniji, ki ne temelji več na organiziranosti združenega dela, pa zakon še vedno ohranja vrsto rešitev, ki spominjajo na staro organiziranost in delovanje univerze. Največji problem izhaja pravzaprav iz splošnega zakona o zavodih, ki je zapolnil praznino ob spremembi pravnega sistema in je $\vee$ mnogočem pomanjkljiv in nejasen. Nejasne so pravice, obveznosti in položaj ustanoviteljev, nejasen je lastninski in premoženjski status zavodov, nejasno je financiranje javnih zavodov in $s$ tem povezano vprašanje tržnih dejavnosti zavodov, nejasno je razmerje med javnimi in zasebnimi zavodi in še vrsta drugih vprašanj. 'Zakon o visokem šolstvu kot poseben predpis se nanj navezuje že s tem, ko opredeljuje univerze, fakultete, umetniške akademije in visoke strokovne šole kot zavode (2. čl. ZViS)

Da bi lahko odgovorili, kakšen je pravni status univerze, je treba najprej proučiti, ali je univerza s sistemsko pravnega vidika korporacija ali ustanova. Iz te temeljne opredelitve izhajajo vse nadaljnje izpeljave organiziranosti, organov in upravljanja, položaj ustanovitelja, lastnina in upravljanje sredstev pa tudi položaj zaposlenih. $\vee$ razpravi bomo pojasnili pravni status univerze in njenih članic glede na veljavno ureditev in jo primerjali z ureditvami $v$ svetu.

Delitev pravnih oseb na korporacije in ustanove je temeljna delitev pravnih oseb in jo priznavajo $\vee$ vseh državah kontinentalnega pravnega sistema. Ta delitev izvira že iz rimskega prava, ki loči korporacije kot združenje oseb (universitas personarum) in ustanove kot skupnost premoženja (universitas bonorum, universitas rerum).

Naša izhodiščna hipoteza je, da sedanja pravna ureditev organiziranosti visokega šolstva ni konsistentna in je neke vrste hibrid dveh konceptov organiziranosti, dveh organizacijskih oblik: zavoda (če zavod razumemo kot posebno obliko ustanove) oziroma korporacije, kar povzroča vrsto problemov in težav v praksi. Odločitev za en ali drug tip pravne osebe bi prispevala $k$ jasnejšemu razumevanju položaja univerze, njenih organizacijskih delov (članic), drugih visokih šol in $\mathrm{k}$ s tem povezanimi statusnimi in drugimi pravnimi rešitvami.

\section{Je univerza korporacija ali ustanova - zavod ?}

Korporacija je združenje oseb pravnih ali fizičnih, ki so njeni člani. Gre za združbo oseb, z njihovo združitvijo pa je ustanovljen nov pravni subjekt, pravna oseba, ki se razlikuje od oseb, iz katerih je sestavljena. Člani korporacije se

1 Vlada je že julija 2004 poslala v prvo obravnava v državni zbor predlog novega zakona, ki pa ni šel $\checkmark$ nadaljno obravnavo in je pričakovati nov predlog zakona. 


\section{Niko Abrahamsberg \\ Pravni ststus univerze in njenih članic}

lahko menjajo in to ne vpliva na njen nadaljnji obstoj. Personalni substrat je torej bistven. Korporacija ima praviloma tudi premoženje, ni pa nujno. Člani korporacije odločajo na podlagi t.i. korporacijskih pravil, ki jih sami sprejmejo (Trstenjak, 2003, str.133). Korporacij imamo več vrst, tako so korporacije na primer: država, občina, gospodarska zbornica, gospodarske družbe, zadruge, društva, itd.

Člani korporacije nimajo stvarnih pravic na premoženju, ampak le t.i. članske pravice $v$ pravni osebi. $\vee$ pravnem prometu nastopajo $v$ imenu korporacije njeni organi (uprava, zastopniki, ipd.). Člani le posredno vplivajo na vodenje in poslovanje korporacije, tako da volijo organe in jim glede na razmere dajejo tudi navodila (Bohinc, 1999, str. 25).

Člani korporacije so lahko fizične in pravne osebe. Najvišji organ te pravne osebe je praviloma zbor vseh članov (npr. skupščina). Ta najvišji organ lahko sprejema tudi t.i. avtonomne odločitve o pravni osebi. Lahko torej odloči o prenehanju, o spremembi namena ipd. Zato $v$ teoriji govorimo o avtonomnosti organov korporacije oziroma o avtonomnih organih. To je tudi bistvena razlika med strukturo in upravljanjem korporacije ter strukturo in upravljanjem ustanove. Ustanove namreč takih avtonomnih organov nimajo (Trstenjak, 2003, str. 135).

Po zakonu o usmerjenem izobraževanju iz leta 1980 bi lahko našo univerzo razumeli kot korporacijo, katere članice so bile samostojne fakultete, ki so se združevale $v$ univerzo in $v$ njej usklajevale svoje interese na podlagi samoupravnega sporazuma. Bistvena značilnost tega jugoslovanskega modela je bila, da so bile fakultete opredeljene kot pravne osebe in izvirne nosilke vseh pravic, s tem da so del teh pravic lahko prenesle na univerzo in na delovno skupnost skupnih služb univerze. Vse pravice so bile delegirane s samoupravnimi sporazumi fakultet. Fakultete so kot članice upravljale univerzo prek univerzitetnega sveta. $\vee$ univerzitetnem svetu so sicer bili tudi predstavniki države, ki naj bi zagotavljali javne interese. Udeležba predstavnikov države in zagotavljanje javnega interesa $v$ tem smislu pomeni odstopanje od koncepta korporacije članic. Univerza ni imela lastnega premoženja.

Drug tip pravne osebe je ustanova. Ustanova je pravna oseba tipa universitas bonorum. Je skupnost premoženja, ki mu je podeljena pravna osebnost. $\checkmark$ teoriji govorimo tudi o personificiranem (namenskem) premoženju. Ustanova per definitionem je na namen vezano premoženje. Premoženje je bistven element ustanove. Poleg premoženja je bistven tudi namen, za katerega veljajo določene posebnosti. Namen pri t.i. tradicionalnih ustanovah je splošno koristen ali dobrodelen. Vendar zlasti novejše zakonodaje dopuščajo tudi ustanove z zasebnimi nameni. Namen je praviloma trajen, izjemoma je dopusten tudi časovno omejen namen. Ustanova ima organ, ki upravlja s premoženjem (npr. uprava) in je praviloma edini obvezni organ ustanove. Ustanova nima 
članov, ima le destinatarje, ki nimajo članskih pravic. Tudi člani uprave ali drugih organov ustanove nimajo članskih pravic. Ustanova torej nima oseb s posebnimi članskimi pravicami, kljub temu pa brez določenih oseb ne more obstajati. Pred ustanovitvijo je to ustanovitelj, po ustanovitvi pa vsaj uprava oziroma drug organ, ki upravlja s premoženjem (Trstenjak, 2003, str. 142).

Kot smo že ugotovili, naš zakon o visokem šolstvu določa, da so univerze, fakultete, umetniške akademije in visoke strokovne šole visokošolski zavodi (2. čl. ZViS).

Glede na takšno opredelitev visokošolskih organizacij se nam odpira nekaj vprašanj. Najprej kako razumeti, da so visokošolske organizacije zavodi in kaj so torej zavodi, korporacije ali ustanove?

$\checkmark$ teoriji je obstoj zavodov kot posebne pravne oblike sporen. $V$ zasebnem pravu zavodov sploh ne poznamo.

Zanimivo je, da v državah Evropske unije ni posebnih zakonov o zavodih. Prav tako tudi njihovi civilni zakoniki posebej ne obravnavajo zavodov. Zakon o zavodih ima Hrvaška ${ }^{2}$ in kot edino izjemo srečamo zavode posebej urejene $v$ civilnem zakoniku Liechtensteina. Le $v$ nekaterih ureditvah javnega prava poznamo javne zavode kot posebno statusno pravno obliko.

$\checkmark$ državah Evropske unije torej zavodov kot posebne statusno pravne oblike zasebnega prava ne poznajo. Zato je sporna naša ureditev, ki dopušča ustanavljanje visokih šol kot zasebnih zavodov. "Oblika, ki je pri nas zasebni zavod, je $\vee$ tujini ustanova, kjer velja posebnost glede vrste premoženja in izvajanja namena» (Trstenjak, 2003, str. 350).

Da so zasebne fizične in pravne osebe lahko ustanovitelji visokošolskih organizacij, ni sporno, vendar se te $v$ tujini organizirajo $v$ znanih statusnih oblikah korporacijskega tipa ali $\vee$ ustanovah. Univerze so kot korporacije organizirane $v$ anglo-ameriškem pravnem sistemu, kjer ustanov ne poznajo. Tako sta bili na primer univerzi Oxford in Cambridge ustanovljeni kot gospodarski družbi (Abbott, Pendlebury, 1995, str. 236). ${ }^{\mathbf{3}}$ Le izjemoma so univerze kot posebne pravne osebe korporacijskega tipa poznane $v$ kontinentalni Evropi. Nekaj takih primerov srečamo $\vee$ Nemčiji (Trstenjak, 2003, str. 108). V teh primerih je lahko univerzo razumeti kot skupnost učiteljev, sodelavcev, raziskovalcev in študentov, ki v univerzi uresničujejo svoje pravice in obveznosti.

Glede na vlogo evropske države, ki prevzema odgovornost za izobraževanje in ustvarja možnosti za izobraževanje, so univerze v Evropi praviloma organizirane kot javni zavodi oziroma javne ustanove $v$ tistih sistemih, kjer javnih

2 Zavodi, kot jih poznamo v Sloveniji, so urejeni v "Zakonu o ustanovama" NN št.76/1993, medtem ko se za ustanove v našem pomenu uporabljata izraza "zakladi " in tudi "zadužbine"

3 Univerzi Oxford in Cambridge sta "Chartered Companies", ustanovljeni na podlagi kraljevega ustanovitvenega akta "Charter by the Crown" 


\section{Niko Abrahamsberg \\ Pravni ststus univerze in njenih članic}

zavodov kot posebne oblike ustanove ne poznajo. Izjemoma so univerze organizirane tudi kot ustanove zasebnega prava. $\mathrm{V}$ primeru da univerzo razumemo kot zavod oziroma kot ustanovo, je ta razumljena kot celota sredstev, premoženja ter oseb, učiteljev in sodelavcev, ki uresničujejo namen, za katerega je univerza ustanovljena, to je raziskovati, ustvarjati in poučevati.

Javni zavodi so posebna oblika, ki je izpeljana iz ustanove, kot universitas bonorum. Pripadnost tipu ustanove se kaže $v$ premoženju, v sredstvih, ki jih zagotavlja ustanovitelj za izvajanje javne službe. Prav zaradi izvajanja javne službe pa so za zavod poleg premoženja pomembni tudi drugi pogoji, ki omogočajo trajno in kvalitetno izvajanje dejavnosti. Tu je potrebno poudariti zlasti personalni substrat, zaposlene ki izvajajo dejavnost, zaradi katere je bil zavod ustanovljen. "Za zavod je bistvena zunanje vidna institucija, ki jo sestavljajo osebe in stvari, in v tem se razlikuje od ustanove. Zavodi opravljajo storitve, ki jih mora zagotavljati država. Zavod nima članov, ampak le uporabnike« (Trstenjak, 2003, str. 118).

Za razliko od ustanov zasebnega prava, ki imajo enotno obliko za organiziranje namembnega premoženja, pa se ustanove kot pravne osebe javnega prava praviloma kažejo $\vee$ dveh oblikah. ${ }^{4} \vee$ obliki javnega sklada, ki predstavlja le določeno premoženje, ki se upravlja za uresničitev določenih namenov (spodbujanje razvoja, ustvarjalnosti in tudi za upravljanje z javnimi nepremičninami) in v obliki javnega zavoda, kjer namembno premoženje neposredno služi izvajanju določene dejavnosti, izvajanju določene javne službe (»javni dejavnosti«: v izobraževanju, znanosti, kulturi, zdravstvu, itd.).

Razlika med javnim skladom in javnim zavodom je torej $v$ tem, da je sklad le oblika upravljanja premoženja za določen namen, medtem ko je javni zavod oblika organiziranja premoženja za izvajanje določene dejavnosti, določene javne službe.

Ob tem pa velja dodati, da izvajanje tako imenovanih družbenih dejavnosti ni več monopol javnih institucij, ampak lahko dejavnost izobraževanja, zdravstva, socialnega varstva, itd., izvajajo tudi pravne osebe zasebnega prava. Zato dejavnost ne more biti kriterij organiziranja oziroma izbire pravnoorganizacijske oblike (Abrahamsberg, 1988). Bistven je namen, zaradi katerega se ustanavlja neka organizacija.

Zato bi bilo primerno, da bi zakon določil, da se zasebne visoke šole ustanovijo kot ustanove ali gospodarske družbe (korporacije) in ne kot zasebni

$4 \mathrm{~V}$ Sloveniji se kot posebne osebe javnega prava pojavljajo tudi javne agencije, ki smo jih prevzeli iz anglo-ameriškega pravnega kroga. Njihov status, kot ugotavlja V.Trstenjak, ni primerljiv z ureditvami v drugih evropskih državah. V Avstriji, Nemčiji, Švici in drugih primerljivih državah se kot posebna statusna oblika ne pojavljajo. Po strukturi so blizu zavodom ali v nekaterih primerih tudi javnim skladom (Trstenjak, 2003,120). 
zavodi, ker ta oblika $v$ svetu ni poznana in ker ni posebnih razlogov in argumentov, ki bi govorili v prid takšni obliki. Po drugi strani, uporaba oblike zavoda zamegljuje namen, zaradi katerega je taka visoka šola ali katera koli druga šola ustanovljena. Ni jasno, ali gre za izvajanje pridobitne ali nepridobitne dejavnosti.

Čeprav je zakon o visokem šolstvu (Ur. I. RS 67/93) odpravil samoupravni model univerze, pa je nekaj elementov tega sistema ohranil, predvsem pa so $\mathrm{v}$ praksi fakultete ohranile svoj samostojni položaj. Zakon opredeljuje visokošolske organizacije kot zavode, fakultete in druge zavode znotraj univerze pa kot članice. $\vee$ tem primeru uporabljeni pojem "članice« $\vee$ smislu pravne osebe korporacijskega tipa moti. Članice niso ustanoviteljice univerze in torej ne bi smele imeti in uveljavljati članskih pravic. Tako tudi statusne spremembe ne morejo biti predmet odločitev organov "članic" - fakultet. Tak primer smo v praksi imeli v zvezi z izločitvijo Fakultete za pomorstvo in promet iz Univerze $v$ Ljubljani in njeno vključitvijo v Univerzo na Primorskem. Fakulteto so dejansko postavili $\vee$ položaj korporacijske članice, ki odloča, čeprav bi o statusnih spremembah moral odločati ustanovitelj, v našem primeru torej država. ${ }^{\mathbf{5}}$

Za javne visokošolske organizacije je zavod sprejemljiva oblika. Potrebno pa je dodati, da so zavodi lahko le samostojne organizacije ne pa tudi sestavni deli le-teh. Najbolj problematičen je položaj fakultet, ki so $v$ vseh primerljivih pravnih sistemih obravnavane kot sestavni del univerze in nikoli kot samostojne organizacije. Univerze imajo tudi druge organizacijske dele: oddelke, inštitute, knjižnice itd., in $v$ tem primeru ne delujejo samostojno. Ker so fakultete sestavni del univerze, jih le-ta tudi ustanavlja, spreminja in ukinja. Sporna je naša ureditev in praksa, ko fakultete kot dele univerze ustanavlja država z odloki o oblikovanju univerze in $\mathbf{s}$ tem posega $v$ avtonomijo univerze. ${ }^{6}$ Samostojna organizacija je univerza, lahko pa so samostojne tudi različne visoke šole. Toda fakulteta $\vee$ nobenem primeru ne more biti zavod in torej samostojen pravni subjekt.

Tako je nujno treba spremeniti 2. čl. Zakona o visokem šolstvu, ki med visokošolske zavode prišteva tudi fakultete. Tudi akademije in visoke strokovne šole, ki so organizacijske enote univerze, ne morejo biti zavodi. Zavod je lahko le samostojna visoka šola (visoka strokovna šola, politehnika, akademija) in $v$ nobenem primeru fakulteta ali oddelek (dipartimento, department). Zato bi morali popraviti tudi 11. čl. ZViS. Fakulteta in oddelek ne moreta obstajati izven univerze in ju tudi ni mogoče ustanavljati kot samostojna zavoda. To je po naši

\footnotetext{
5 Zakon o zavodih v 51. čl. določa: Ustanovitelj lahko odloči, da se zavod pripoji drugemu zavodu, da se dvoje ali več zavodov spoji v en zavod ali da se zavod razdeli na dvoje ali več zavodov. Ustanovitelj lahko odloči, da se organizacijska enota zavoda izloči in pripoji drugemu zavodu ali organizira kot samostojni zavod.

6 Nasprotno sicer odločba ustavnega sodišča RS U-I_ 34/94, objavljena v Ur. I. RS 18/1998.
} 


\section{Niko Abrahamsberg}

\section{Pravni ststus univerze in njenih članic}

pravni ureditvi možno in se $v$ praksi tudi izvaja (Fakulteta za podiplomske državne in evropske študije Kranj, Fakulteta za podiplomske humanistične študije Ljubljana in Fakulteta za podiplomski študij managementa Bled), kar je unikum $\checkmark$ svetu. Drugi člen Zakona o visokem šolstvu bi se torej pravilno glasil: "visokošolski zavodi so univerze in samostojne visoke šole«. Potrebno bi bilo doreči, kakšne visoke šole bomo imeli. Vsekakor je vprašanje aktualno v zvezi z uresničevanjem enotnega Evropskega visokošolskega prostora in zahtevami Bolonjske deklaracije.

Nova hrvaška pravna ureditev visokega šolstva, ki izhaja iz enakih preteklih pravnih temeljev kot slovenska, je obravnavani problem delno rešila. "Sveučilišta, veleučilišta $i$ visoke škole osnivaju se kao ustanove», medtem ko so fakultete in akademije opredeljene kot sestavni deli sveučilišta (48. člen Zakona o znanstvenoj djelatnosti i visokom obrazovanju, NN 123/2003).

\section{Pravna subjektiviteta univerze, članic in samos- tojnih visokošolskih zavodov}

Ko je zakon o visokem šolstvu $v$ drugem členu naštel visokošolske zavode, je s tem že opredelil njihovo pravno subjektiviteto. Saj zakon o zavodih kot splošni zakon (lex generalis) opredeljuje zavode kot pravne osebe (1. odst. 4. čl. ZZ). Kljub temu pa zakon o visokem šolstvu še posebej v 10. čl. ureja pravni status univerze in njenih članic.

Zakon izrecno določa, da je univerza pravna oseba. Hkrati pa zakon za članice univerze ni izrecen in nejasno opredeljuje njihov status. $V$ vseh primerljivih pravnih sistemih je jasno, da fakultete in oddelki univerze niso pravne osebe. Tako na primer statut češke tehniške univerze $v$ Pragi $\vee 24$. členu izrecno določa, da fakultete niso pravne osebe in tudi v 25. členu, da inštituti znotraj univerze niso pravne osebe.

Posredno bi lahko pri nas s sklepanjem ad contrario prišli do zaključka, da fakultete, akademije in visoke šole $v$ sestavi univerze niso pravne osebe. Namreč 11. čl. ZViS, določa: "Fakultete in umetniške akademije, ki niso javni visokošolski zavodi, in visoke strokovne šole se lahko ustanovijo kot samostojni visokošolski zavodi in so pravne osebe«. In obratno velja sklepanje, da fakultete in akademije, ki so javni visokošolski zavodi, ne morejo delovati kot samostojni visokošolski zavod in ne morejo biti pravna oseba. Ostaja pa temeljni ugovor o poimenovanju oziroma opredelitvi fakultet kot zavodov. 
Prav tako nejasen je položaj »drugih zavodov « znotraj univerze. ${ }^{7}$ Vprašanje je ali so knjižnice, inštituti in druge organizacije, katerih dejavnost je potrebna za uresničevanje visokošolske dejavnosti, in študentski domovi pravne osebe. Zakon o visokem šolstvu jih imenuje "drugi zavodi - članice univerze« in v 2. odst. 1. čl. napoveduje ureditev njihovih statusnih vprašanj $v$ istem zakonu. $V$ nadaljevanju zakon njihovega pravnega statusa ne obravnava posebej, ampak enotno uredi v 10. čl. za vse članice univerze enako in enako nejasno. Drugi zavodi - članice univerze niso izrecno priznani kot pravne osebe, nastopajo pa $v$ svojem imenu in za svoj račun, kadar ne izvajajo nacionalnega programa visokega šolstva.

Čeprav "članice« niso pravni subjekt, niso pravne osebe, pa kot deli pravne osebe lahko imajo določene pravice in obveznosti. $V$ tem primeru bi govorili, da imajo "članice" omejeno pravno sposobnost, torej sposobnost biti nosilec določenih pravic in obveznosti, ki jih nanje prenese pravna oseba - univerza. Zakon jasno določa, da imajo "članice univerze" pravice in obveznosti, določene z zakonom, aktom o ustanovitvi univerze in statutom univerze (2. odst. 10. čl. ZViS). Takšen položaj članic zahteva, da le-te $v$ pravnem prometu nastopajo vedno $v$ imenu univerze. ${ }^{\mathbf{8}}$

Ko gre za izvajanje nacionalnega programa visokega šolstva, za katerega zagotavlja sredstva Republika Slovenija, naš zakon določa, da "članice» nastopajo $\vee$ imenu univerze in tudi za račun univerze $\vee$ mejah pooblastil, ki jih določata akt o ustanovitvi univerze in njen statut (3. odst. 10. čl.). V tem primeru gre za omejeno poslovno sposobnost članic, ki lahko sklepajo le tiste pravne posle, za katere so pooblaščene, vendar pravice in obveznosti gredo univerzi, kot pravni osebi.

Posebno vprašanje je, ali lahko univerza in njene članice nastopajo tudi na trgu in pridobivajo dohodek oziroma dobiček. Zakon o zavodih to omogoča, saj predvideva, da zavod sredstva za delo lahko pridobiva tudi na trgu s prodajo blaga in storitev z omejitvijo, da se presežek prihodkov nad odhodki (dobiček) sme uporabiti le za opravljanje in razvoj dejavnosti (48.čl. ZZ). Odprto ostaja vprašanje, koliko se to sklada $z$ opredelitvijo $v$ prvem členu istega zakona, da cilj opravljanja dejavnosti ni pridobivanje dobička. Zakaj bi sicer sploh nastopali

\footnotetext{
7 Univerza $\vee$ Ljubljani takih članic nima, Univerza $\vee$ Mariboru pa $\vee$ svojem statutu določa da sta "drugi članici" univerzitetna knjižnica in študentski domovi.

8 Tako $\vee$ prevodu statuta $\vee$ angleški jezik že omenjene češke tehniške univerze $\vee$ Pragi, 24. čl. določa: „Faculties are not legal entities. In all maters given in \& 24 par.1 of Act, belonging to the independent fields of action of faculties, they are entitled to make decisions, or in legal relations they are entitled to act on behalf of CTU through faculty organs. "In dalje" Within the powers delegated by the Rector, the deans or other delegated faculty staff members are entitled to act on behalf of CTU".
} 


\section{Niko Abrahamsberg \\ Pravni ststus univerze in njenih članic}

na trgu? Država prihodke nad odhodki obdavči kot dobiček in to enako kot pri podjetjih. Pravzaprav zavode obravnava enako kot druge gospodarske subjekte. ${ }^{\mathbf{9}}$

Nesporno je, da univerza lahko nastopa na trgu neposredno, lahko pa tudi prek članic. Seveda pa ni pričakovati, da bi članice nastopale na trgu, če $v$ tem ne vidijo svojo neposredno korist. Zato $v$ teh primerih članice nastopajo $v$ imenu univerze vendar za svoj račun.

Povsem $v$ nasprotju z ugotovitvijo, da članice niso pravne osebe, je ureditev $\vee$ zakonu, ki določa, da članice $v$ primerih ko ne gre za nacionalni program, nastopajo $\vee$ svojem imenu in za svoj račun (4. odst. 10. čl.). Takšna dikcija bi pomenila, da smo članicam priznali samostojnost in pravno subjektiviteto, saj lahko le samostojni subjekti, pravne osebe nastopajo $v$ svojem imenu. $V$ svojem imenu in za svoj račun ali tuj račun lahko nastopajo le pravne osebe oziroma fizične osebe, kot samostojni pravni subjekti.

Razumevanje pravnega položaja članice ni pomembno le zaradi nastopanja na trgu, ampak tudi v vseh drugih pravnih situacijah. $Z$ delovno pravnega vidika se zastavlja vprašanje, kdo je subjekt, s katerim sklepa delavec delovno razmerje, univerza ali članica. $S$ procesnega vidika je vprašanje, ali je stranka $v$ postopku univerza ali članica. Z vidika odškodninske odgovornosti pa vprašanje, kdo odgovarja za obveznosti, ki jih prevzema članica. Pomembno je vprašanje, kdo je lastnik premoženja, univerza ali članica, itd.

$\mathrm{Na}$ vsa navedena vprašanja ni mogoče zadovoljivo odgovoriti glede na napačno opredelitev pravne subjektivitete članic $\vee 4$. odst. 10. čl. ZViS. Težko je pristati na interpretacijo, da so članice univerze pravne osebe, ko nastopajo na trgu $v$ svojem imenu in za svoj račun in da niso pravne osebe, ko izvajajo nacionalni program. $V$ pravni teoriji ne poznamo pravnih oseb, ki bi imele $\vee$ različnih situacijah različen status. Organizacija torej je ali pa ni pravna oseba.

Kranjc ugotavlja, da je šlo za kompromis, s katerim se je zakonodajelec hotel izogniti nasprotovanju dotlej samostojnih fakultet. Tako lahko članice univerze zunaj svoje poglavitne dejavnosti, ki jo financira država, še naprej delujejo samostojno. In kot ugotavlja, ta deljena pravna sposobnost povzroča nekatere praktične probleme (Kranjc, 1999. str. 211).

Na drugi strani je na mestu opredelitev $\vee$ 11. čl. ZViS, da so samostojni visokošolski "zavodi « pravne osebe. Ostaja sicer temeljni ugovor, da v svetu ne poznajo samostojnih zasebnih zavodov, zasebne visokošolske organizacije bi morale biti ali ustanove ali gospodarske družbe. Nesprejemljiva pa je $v$ tem členu zakona umestitev fakultet med samostojne visokošolske zavode. Ne v pravni ureditvi in ne $v$ praksi kontinentalne Evrope nismo zasledili primerov, ko

9 Zakon o finančnem poslovanju podjetij (UI. RS 54/99) v 7. točki prvem členu določa: "Podjetje je gospodarski subjekt organiziran kot gospodarska družba, podjetnik, zavod ali zadruga. 
bi bile fakultete samostojne organizacije z lastno pravno subjektiviteto. Fakultete se vedno pojavljajo kot sestavni deli univerze in $v$ skladu $z$ univerzitetno avtonomijo so univerze same določajo svojo notranjo organizacijo in s tem tudi ali in koliko fakultet oziroma oddelkov bodo imele. ${ }^{\mathbf{1 0}}$ Tuje ureditve pa poleg univerz poznajo tudi samostojne visoke šole, kar je običajno.

Fakultet ne gre enačiti z ameriškimi, kanadskimi in angleškimi kolidži (college). Kolidži so lahko deli univerze, lahko pa so tudi povsem samostojne institucije. Kolidži izvajajo dvoletne ali štiriletne programe. Ameriške univerze so zelo različno strukturirane in imajo $v$ svoji sestavi tako kolidže kot tudi poklicne šole (professional school of education, law, medicine, engineering, itd). ${ }^{11} \mathrm{Na}$ drugi strani pojem faculty pri njih pomeni učiteljsko in administrativno osebje univerze in ne organizacijske enoto, kot to velja za kontinentalne univerze. ${ }^{\mathbf{1 2}}$

\section{Ustanovitev in premoženje univerze, članic oziroma samostojnih visokošolskih organizacij (zavodov)}

Univerzo in samostojne visokošolske organizacije lahko ustanovijo domače in tuje fizične in pravne osebe. Javne visokošolske zavode: univerze, fakultete, umetniške akademije in visoke strokovne šole ustanavlja Republika Slovenija. Republika Slovenija ustanavlja tudi študentske domove ter knjižnice, inštitute in druge zavode znotraj univerze, torej članice univerze (9. čl. ZViS). Če fakultete in drugi deli univerze niso pravne osebe, potem je sporno ustanavljanje teh notranjih organizacijskih delov. Organiziranje fakultet, oddelkov, inštitutov znotraj univerze je stvar univerzitetne avtonomije, kar določa tudi naš zakon (2. alineja, drugega odstavka 6. čl. ZViS). Če pogledamo v tuje ureditve, ugotovimo, da odločitve o organiziranosti univerze sprejema senat univerze. ${ }^{\mathbf{1 3}}$

Zakon o visokem šolstvu ne pozna in ne ureja obdobja $v$ ustanavljanju. Tako ne obstaja status "univerze v ustanavljanju», kar ni nič narobe, vendar pa

10 Tako na primer statut Univerze v Sieni v 5. čl. določa: „Universita ha autonomija statutaria, regolamentaria, organizzativa, finanziaria e contabile." In dalje $\vee$ 19. čl. "Le Facolta sono le strutture didattiche della Universita di Siena."

11 Colleges and Universities, URL= http:// Encarta.msn.com/encnet/refpages/RefArticle.asp

$12 \mathrm{~V}$ slovarju Webster: faculty - the entire teaching and administrative force of a university, college, or school.

13 Islandski zakon o univerzi "The University Act, No.136" od 23. decembra 1997, na primer v 16. čl. določa: "The Senate shall decide on division into faculties." In dalje v 17.čl. „The Senate may, upon receipt of proposals from a faculty, divide the faculty in question into departments." Enako tudi hrva'ki zakon o znanstvenoj delatnosti i visokom obrazovanju v 48.členu: "Sveučilište može osnovati i u svom sastavu imati fakultete, umjetničke akademije i odjele te druge sastavnice sakladno zakonu." 


\section{Niko Abrahamsberg \\ Pravni ststus univerze in njenih članic}

je $v$ tem primeru treba ločiti samo ustanovitev univerze, ki je pravno dejanje sprejema akta o ustanovitvi, od začetka opravljanja dejavnosti, ki je vezana na materialno izgradnjo in izpolnjevanje predpisanih pogojev. Vprašanje je ali je realno zahtevati, da ima visokošolska organizacija pred ustanovitvijo zagotovljene prostore, opremo ter učitelje, znanstvene delavce in visokošolske sodelavce. Nekoliko jasnejše se zdi vprašanje premoženja. Univerza oziroma samostojni visokošolski zavod, ki ga je ustanovila Republika Slovenija, je lastnik premoženja, pridobljenega iz javnih sredstev in drugih virov (1. odst. 13. čl. ZViS). Zakon univerzo in samostojne zavode omejuje $v$ razpolaganju $z$ nepremičninami in javnimi sredstvi večje vrednosti. Ničesar zakon ne pove o lastnini "zasebnih zavodov«. Različno bi obravnavali premoženje zasebne šole, če gre za ustanovo, in drugače, če gre za gospodarsko družbo.

Zastavlja se tudi vprašanje ali lahko ustanovimo univerzo oziroma visoko šolo brez premoženja. Zakon o zavodih določa, da mora ustanovitelj zagotoviti sredstva za ustanovitev in začetek dela zavoda (7. čl. Zakona o zavodih). Zakon o visokem šolstvu je nekoliko preciznejši in določa, da se visokošolski zavod lahko ustanovi, če so zagotovljeni ustrezni prostori in oprema za izvedbo programa (14. čl. ZViS). Vendar pa praksa kaže, da se zasebni visokošolski zavodi ustanavljajo tudi brez premoženja. Prostori in oprema se zagotovijo z najemom. Stroškov najema ne pokrivajo ustanovitelji ampak zavod iz svoje dejavnosti, oziroma če smo konkretnejši, iz šolnin izrednih študentov. Če zasebni zavod pridobi še koncesijo za izvajanje dejavnosti, potem ustanovitelji ne prevzemajo nobenega rizika ustanovitve visokošolskega zavoda. $V$ aktu o ustanovitvi lahko svojo odgovornost za obveznosti zavoda tudi izključijo (2. odst. 49. čl. Zakona o zavodih). Ker zavod nima nobenega ustanovitvenega premoženja oziroma ima le premoženje pridobljeno iz dejavnosti na trgu, varstvo upnikov ni zagotovljeno. Povsem drugačna pravna varnost bi bila zagotovljena, če bi visoko šolo ustanovili kot ustanovo ali gospodarsko družbo. Zanimiva je določba Hrvaškega zakona o zavodih, ki $\vee 2$. odstavku 1. člena izrecno določa, da se za pravne osebe, ki opravljajo dejavnost vzgoje in izobraževanja in druge "družbene dejavnosti« pridobitno, uporabljajo določbe zakona o gospodarskih družbah (zakona o trgovačkim društvima). Tudi država kot ustanovitelj je svojo odgovornost omejila le na sredstva, ki jih je zagotovila za delovanje univerze in članic. Torej na premoženje, $\mathrm{ki}$ je $\mathrm{v}$ lasti univerze in $\mathrm{s}$ katerim ta kot lastnica razpolaga. Z drugimi besedami, država za obveznosti univerze ne odgovarja (19. čl. Odloka o preoblikovanju Univerze $v$ Ljubljani). Stvari se zapletejo tudi pri vprašanju ali so deli univerze, torej fakultete, akademije, visoke strokovne šole in drugi zavodi lahko lastniki premoženja. Iz dikcije zakona sledi, da "visokošolski zavodi« upravljajo in razpolagajo s premoženjem, ki ga uporabljajo za opravljanje svoje dejavnosti $v$ skladu $z$ aktom o ustanovitvi in statutom, če z zakonom ni drugače določeno (2. odst.13. čl. ZViS). Pri tem je za pravnike jasno, da razpolagati s premoženjem 
pomeni tudi premoženje odtujiti ali obremeniti in da s premoženjem lahko razpolaga le lastnik. $\vee$ povezavi z drugim členom zakona o visokem šolstvu, ki določa, da so "visokošolski zavodi«: fakultete, umetniške akademije in visoke strokovne šole, lahko zaključimo, da so le-te lahko lastniki premoženja. Ker so lahko lastniki le pravni subjekti, bi to pomenilo, da so fakultete in drugi deli univerze pravne osebe. Tej interpretaciji so sledile tudi naše univerze, ki določajo: da "članice razpolagajo z nepremičninami« (347. čl. statuta Univerze v Mariboru), "članica samostojno razpolaga s premoženjem, pridobljenim z dejavnostjo iz 16. čl. " Gre za dejavnosti, ki se izvajajo na trgu (264. čl. statuta Univerze v Ljubljani), in še bolj jasno "članice univerze so lastnice premoženja, pridobljenega na osnovi drugih virov« (196. čl statuta UP). Torej tudi v tem primeru pravna ureditev ostaja nejasna. Zato bi morali drugi odstavek 13. čl. črtati, ali zapisati: Premoženje, pridobljeno iz javnih sredstev, se uporablja $v$ skladu z namenom, za katerega je bilo pridobljeno oziroma zagotovljeno. Zanimivo je, da fakultete in drugi deli univerze pri razpolaganju niso omejeni tako kot univerza in samostojni visokošolski zavodi, ki lahko premoženje pridobljeno iz javnih sredstev odtujijo ali obremenijo le s soglasjem ustanovitelja (3. odst. 13. čl. ZViS). Saj v drugem odstavku 13. čl. zakon govori o visokošolskih zavodih, ki imajo pravico upravljati in razpolagati, medtem ko $v$ tretjem odstavku izrecno navaja omejitve le za univerzo in samostojne visokošolske zavode. Prav tako zanimivo je, da statut Univerze $\vee$ Ljubljani pogojuje odtujitev oziroma obremenitev nepremičnin ali opreme večje vrednosti s soglasjem univerze. S tem se univerza postavlja $v$ položaj ustanovitelja članice.

Glede na to, da smo opustili družbeno lastnino in ponovno vzpostavili lastninske temelje pravne ureditve, je nujno, da spremenimo tudi upravičenja, ki so izhajala iz družbene lastnine, to je pravici »upravljanja in razpolaganja«. Tako nova pravna ureditev upravičenje "upravljanja « z lastnino ne pozna več. Lastninska pravica lastniku zagotavlja uporabo, užitek in razpolaganje s stvarjo (37. čl. Stvarnopravnega zakonika). Le zakon lahko uporabo, užitek in razpolaganje omeji. S tega vidika je sporna določba 264. čl. statuta Univerze $\vee$ Ljubljani, ki članico univerze omejuje $v$ njenem razpolaganju.

\section{Kdo je delodajalec, univerza ali članica}

Zakon o visokem šolstvo poleg drugih delovno pravnih predpisov posega tudi $v$ opredelitev položaja zaposlenih na univerzi oziroma $v$ članici. Problem se s statusno pravnega vidika, ko ni jasna pravna subjektiviteta članic, kaže $v$ vprašanju kdo je delodajalec, univerza ali članica. 


\section{Niko Abrahamsberg \\ Pravni ststus univerze in njenih članic}

Zakon o delovnih razmerjih $\vee 5$. členu določa, da je delodajalec pravna oseba, ki zaposluje delavca na podlagi pogodbe o zaposlitvi. Sedanja praksa na naših univerzah kaže, da formalno kot delodajalec nastopa univerza, čeprav si vrsto pristojnosti iz delovnopravnih razmerij delita rektor kot zastopnik univerze in dekan fakultete na podlagi pooblastila rektorja. Tako na primer o zaposlitvi nepedagoških delavcev fakultete odloča dekan, ki po pooblastilu tudi podpisuje te pogodbe o zaposlitvi.

Ker je delodajalec univerza in ne članica, bi torej univerza morala zagotavljati vse pravice in izpolnjevati obveznosti iz delovnega razmerja. $\vee$ praksi ugotavljamo, da zaposleni uveljavljajo svoje pravice pri posameznih članicah. Plača in druge pravice se uresničujejo na podlagi splošnih aktov članic. Posamezne pravice in zlasti plače se ne glede na skupna merila bistveno razlikujejo med seboj, kar je posledica različnih prihodkov iz dejavnosti na trgu.

Stvari se zapletejo, ko določena oseba v okviru svojega polnega delovnega časa opravlja delo pri dveh ali več članicah. Tako se zgodi, da za enak obseg dela prejema različen dohodek, kar ni sprejemljivo.

Visokošolski učitelj oziroma znanstveno-raziskovalni sodelavci lahko opravljajo delo tudi preko polnega delovnega časa do ene petine delovnega časa pri drugem delodajalcu, torej pri drugi univerzi ali drugem samostojnem zavodu $v$ skladu s 146. čl. zakona o delovnih razmerjih. Novela zakona o visokem šolstvu je to pravico do dopolnilnega dela omogočila tudi pri istem delodajalcu-univerzi za visokošolske učitelje in sodelavce, ne pa znanstvene delavce (9. odst. 5. čl. zakona o spremembah in dopolnitvah zakona o visokem šolstvu, Ur. I. RS 100/2003).

$\checkmark$ tem primeru zakon ne zahteva soglasja članice za delo pri drugi članici, lahko pa bi to določal statut univerze. Soglasje delodajalca pa si mora pridobiti visokošolski učitelj, če opravlja delo po podjemni pogodbi (pogodbi o delu) pri drugem delodajalcu.

Ko govorimo o delu preko polnega delovnega časa pri istem delodajalcu, se sedaj srečamo z različnimi vrstami dela, to je z nadurnim delom, dodatno tedensko pedagoško obveznostjo in dopolnilnim delom.

Posebej se zastavlja vprašanje zaposlovanja delavcev, ki opravljajo dela, ki jih je fakulteta-članica opredelila kot dejavnost za trg in članica $\vee$ tem primeru nastopa $\vee$ svojem imenu in za svoj račun, torej kot pravna oseba. Zanimiva je tu določba statuta Primorske univerze, ki določa da članice za izvajanje dejavnosti na trgu zaposlujejo $v$ skladu s svojimi pravili, ki jih sprejme upravni odbor članice (24. člen statuta UP). 


\section{Zaključek}

Analiza zakona o visokem šolstvu je pokazala vrsto nejasnosti in sistemskih težav. Zakonodajalec je univerzo in samostojne visokošolske organizacije opredelil kot zavode in ne kot korporacije, ni pa dosledno temu izpeljal celotne ureditve statusa visokošolskih organizacij. Ker zakon o zavodih kot lex generalis opredeljuje zavode kot pravne osebe, je jasno, da je univerzam in samostojnim visokim šolam priznana pravna subjektiviteta. To še posebej poudari 10. čl zakona o visokem šolstvu, ko zapiše, da je univerza pravna oseba, in v 11. čl., ko zapiše, da so samostojni visokošolski zavodi pravne osebe.

Sporen je položaj delov univerze, torej fakultet, akademij, visokih strokovnih šol, inštitutov in drugih "zavodov", za katere zakon ne navaja, da so pravne osebe, določa pa nepravilno, da so visokošolski zavodi. Pravne osebe so le tiste organizacije, tisti subjekti, ki jim pravni red to lastnost daje. Fakultete kot sestavni deli univerze ne morejo biti samostojni zavodi in ne samostojne pravne osebe, če se zgledujemo po univerzah kontinentalne Evrope.

Če deli univerze: fakultete, akademije in visoke strokovne šole niso pravne osebe, potem ne morejo nastopati $v$ svojem imenu, lahko nastopajo le $v$ imenu univerze. Prav tako ne morejo razpolagati in imeti svojega premoženja, lahko pa uporabljajo premoženje univerze za izvajanje dejavnosti, še posebej to velja za premoženje in sredstva, ki so bila pridobljena z izvajanjem njihove dejavnosti na trgu.

Zavod tudi ne more imeti članic, ima le organizacijske dele (fakultete, akademije), ki imajo lahko večjo ali manjšo avtonomijo. Deli univerze imajo lahko tudi večja ali manjša pooblastila v pravnem prometu.

Ne glede na to, da fakultete oziroma akademije in visoke strokovne šole znotraj univerze nastopajo na trgu, bi morale nastopati v imenu univerze, četudi za svoj račun. Ker članice lahko opravljajo dejavnosti na trgu le na podlagi statuta univerze in v obsegu, ki ga le ta določa, se mora univerza s "članicami« dogovoriti o načinu zagotavljanja sredstev za izpolnjevanje obveznosti iz prevzetih poslov na trgu in s tem povezanim vprašanjem odgovornosti univerze napram upnikom. Na drugi strani se je potrebno dogovoriti o pravicah članic, ki izhajajo iz poslov, sklenjenih na trgu.

Posebej bo treba urediti položaj visokošolskih organizacij, ki niso javni visokošolski zavodi. Seveda je to vprašanje vezano na splošno ureditev in spremembo zakona o zavodih, ki bi po našem mnenju moral opustiti obliko zasebnih zavodov in jo nadomestiti s poznanimi pravnoorganizacijskimi oblikami zasebnega prava. Vsekakor bi morali dopustiti, da se dejavnost visokošolskega izobraževanja izvaja tudi pridobitno, kar zasebni zavodi $v$ praksi že izvajajo. Tudi če bi se ustanovitelji odločili, da bi to dejavnost izvajali nepridobitno, 


\section{Niko Abrahamsberg \\ Pravni ststus univerze in njenih članic}

oblika zasebnega zavoda ni primerna. Zakon o gospodarskih družbah nam ponuja možnost oblikovanja tako pridobitne, kot tudi nepridobitne gospodarske družbe (1. člen in še posebej 4. odstavek 1. člena ZGD).

Niko Abrahamsberg je magister pravnih znanosti in višji predavatelj na Fakulteti za upravo Univerze $v$ Ljubljani ter na Fakulteti za management Univerze na Primorskem, kjer predava Gospodarsko pravo.

\section{Literatura in viri}

- $\quad$ Abbott K. R., Pendlebury N. (1995): Business Law, London 1995.

- $\quad$ Abrahamsberg, N. (2000): Nova pravna ureditev zavodov; Zbornik referatov, Dnevi slovenske uprave; Visoka upravna šola, Portorož 2000.

- $\quad$ Abrahamsberg, N. (1988): Dejavnost; Zbornik znanstvenih razprav, Visoka upravna šola, Ljubljana 1988.

- Bohinc, R. (1998): Razlikovanje na pravne osebe javnega in zasebnega prava; Podjetje in delo Ljubljana 8/1998

- $\quad$ Bohinc, R., Bratina, B., Pivka H. M. ( 1990): Pravo gospodarskih družb; FDV Ljubljana 1990.

- Kranjc, J. (1999): Zakonska ureditev visokega šolstva; Zbornik znanstvenih razprav, PF Ljubljana 1999.

- $\quad$ Pirnat, R. (1999): Vrsta in značilnosti pravnih oseb - pravne osebe javnega prava sistem ali kaos; Podjetje in delo, Ljubljana 6/1999.

- Ragonesi, V. ( 1985): Diritto amministrativo: ed. Pirola, Milano

- Toplak, L.(2003): Zakaj je pravni status univerze v Evropi tako pomemben, dnevnik Delo, 22. november 2003.

- Trpin, G. (2005): Javne službe in javni zavodi, Podjetje in delo, Ljubljana 6-7/2005.

- Trstenjak, V. (2003): Pravne osebe; GV Ljubljana 2003.

- Zakon o visokem šolstvu, Ur. I. RS, 67/93, 39/95-US, 18/98- US, 35/98-US, 99/99, 64/2001, 100/2003

- Zakon o zavodih, Ur. I. RS, stari -12/91

- Zakon o ustanovah, Ur. I. RS 60/95

- Zakon o javnih skladih, Ur I. RS, 22/2000

- Zakon o finančnem poslovanju podjetij, Ur. I. RS, 54/99

- Zakon o ustanovama, Hrvaške NN 76/93 
- Zakon o znanstvenoj djelatnosti i visokom obrazovanju, Hrvaške NN 123/2003

- $\quad$ The Universities Act, Iceland, No.136/1997

- $\quad h t t p: / /$ brunnur.stjr.is/mrn/mrn-en...

- $\quad$ Statut Univerze v Ljubljani, Ur. I. RS 64/2001

- $\quad$ Statut Univerze v Mariboru, Ur. I RS 19/2001

- $\quad$ Statut Univerze na Primorskem, Ur. I. RS 73/2003

- $\quad$ Odlok o preoblikovanju Univerze v Ljubljani, Ur. I. RS 28/2000

- $\quad$ Statuto della Universita degli studi di Siena

- $\quad$ Statute of the Czech technical university in Prague

- $\quad$ Statute for the University of Copenhagen

- The General Rules Concerning University Organization and Procedure of Illinois

- Colleges and Universities - http://Encarta.msn.com/encnet/refpages/RefArticle.aspx?refild=761553412\&pn=1 
Niko Abrahamsberg

Pravni ststus univerze in njenih članic

\section{SUMMARY}

\section{Legal Status of the University and its Members}

In this paper the author deals with the legal status of the University and its constituent parts. His conclusion is that it differs greatly from legal arrangements elsewhere in the world and that it represents a kind of a mixture between a corporation and an institution. What is particularly disturbing is the unclear status of the University's parts - Faculties, Academies, institutions of higher education and other organisations, to which the law recognizes the corporative status of members on one hand, and defines them as institutions on the other.

A corporation is an association of legal and natural persons which are its members. We are dealing with an association of persons, and with their merger a new legal person or entity is established which differs from the persons which constitute it. Members of a corporation may change yet this does not affect its further existence. The substratum of persons is therefore essential.

According to the Career-Oriented Education Act (Zakon o usmerjenem izobraževanju) adopted in 1980, our University can be considered a corporation, the members of which were independent Faculties which merged into the University and which, within its framework, co-ordinated their interests on the basis of a self-governing agreement. The main characteristic of this Yugoslavian model was that Faculties were defined as legal persons and original holders of all rights; they could transfer part of these rights to the University and the work community of the University's joint services. All rights were delegated on the basis of the Faculties' selfgoverning agreements. As members they managed the University through the University Council. The University Council also included state representatives whose aim was to represent public interests. The University did not have any of its own assets.

Public institutes are a special form which is derived from an institution as universitas bonorum. Affiliation to a certain type of institution is reflected in the assets and funds guaranteed by the founder for the purpose of performing public services. It is precisely for the performance of public services that, in addition to the assets, other conditions are important for public institutions, those which guarantee permanent and quality performance of activities. One particular element is the personnel substratum or employees who perform an activity for which the institution was 
established. Essential for the public institute is an externally recognizable institutional structure which is comprised of persons and material things which distinguish it from an institution. Institutes perform services which must be provided by the state. Institutes do not have members, only users.

Although the Higher Education Act (Official Gazette of the Republic of Slovenia no. 67/93) has abolished the self-governing model of the University, it has nevertheless retained some elements of this system and the faculties in particular have retained their independent status in practice. The Act defines higher education organisations as institutes, while Faculties and other institutions within the University are considered to be members. In this case, the applied term "members" in terms of a legal person of the corporation type is disturbing. For public higher education organisations the institute is an acceptable form. What needs to be mentioned is that only institutes can be independent organisations and not their constituent parts. Most problematic of all is the status of faculties which are, in all comparable legal systems, considered to be constituent parts of the University and never independent organisations. The Act explicitly states that the University is a legal person, while it does not explicitly define the status of University members which to a large extent remains unclear.

Somewhat clearer is the issue of assets. The University or an independent higher education institution established by the Republic of Slovenia is the owner of assets acquired from public funds and other resources. The Act imposes restrictions on the University and independent institutions with regard to the disposal of real estate and public assets of greater value. The Act does not deal with the assets of "private institutes". With regard to this, different treatment would apply for institutions on the one hand and to companies on the other.

Due to the fact that it is the University who is the employer and not its members, the University should this guarantee all rights and comply with the obligations arising from the employment relationship. The practice shows that employees exercise their rights within the framework of individual members. Salary and other rights are exercised on the basis of members' general legal acts. Irrespective of the common criteria, individual rights and especially salaries differ significantly, which is the result of different income generated by means of market activities.

As the Institutes Act, as the lex generalis, defines institutes as legal persons, it is clear that a legal personality is recognized by universities and independent institutions of higher education. What is disputable is 
Niko Abrahamsberg

Pravni ststus univerze in njenih članic

the status of University parts, namely the faculties, academies, professional colleges, institutes and other "institutions" for which the Act does not stipulate whether they are legal persons and incorrectly defines them as higher education institutions. Legal persons are only those organisations and those entities to which the law grants this nature. Faculties as constituent parts of the University can be neither independent institutions nor independent legal persons if we take into consideration the universities of continental Europe. If parts of the University, such as the faculties, academies, professional colleges, are not legal persons, then they cannot act on their OWN behalf but only on behalf of the University. Nor can they dispose of and have their own assets but they can USE the University's assets for the performance of their activities; this is particularly true for assets and resources which have been generated by the performance of their activity in the market.

Institutes cannot have MEMBERS but only organisational parts (faculties, academies) which can have greater or lesser autonomy. Parts of the University can also have greater or lesser powers in legal matters. Irrespective of the fact that the Faculties, Academies and professional colleges operate on the market, they should act on behalf of the University, even though it is for their own benefit. As members can carry out market activities only on the basis of the University Statute and to the extent defined therein, the University must, together with its "members", agree on the manner of the provision of funds for the performance of obligations arising from market activities and the related issue of the responsibility of the University towards creditors. On the other hand, the rights of members which arise from business activities concluded on the market also need to be agreed upon.

The status of higher education organisations which are not higher education institutes has to be regulated separately. Of course this issue is related to the general arrangements and an amendment to the Institutes Act which, in our opinion, will have to suspend the form of private institutes and replace it with the existing legal organisational forms of private law. It should, by all means, be allowed that higher education activities are also carried out as gainful activities, something which is already in practice at private institutes. Even if the founders decided that this activity would be performed in a non-profit manner, the form of a private institute is not adequate. The Companies Act offers us the possibility of establishing both for-profit and non-profit companies. 